Dikirim: 19 Januari 2017 Diterbitkan: 1 September 2017

\section{Faktor risiko kegagalan pengobatan ulang pasien tuberkulosis di Yogyakarta}

\author{
Risk factors of unsuccess retreatment among tuberculosis \\ patients in Yogyakarta \\ Suharna $^{1} \&$ Ning Rintiswati ${ }^{2}$
}

\section{Abstract}

Purpose: The purpose of this study was to identify risk factors related to unsuccessful retreatment of tuberculosis cases in Yogyakarta. Methods: A case-control study was conducted at the health offices of five districts from the tuberculosis registry (TB 03 and TB 01) since 2008-2014. Case group criterion was defined as unsuccessful retreatment of tuberculosis patients, whereas the control group consisted of successful retreatment of tuberculosis patients (cure or complete treatment). A total of 142 cases and 142 controls were analysed with univariate, bivariate, and multivariate analyses. Chi-square tests were conducted with $p<0.05$ and odds ratio (OR) at confidence interval 95\%. Results: Bivariate analysis showed that regular taking of a drug, conversion of acid-fast bacilli, and type of health services were statistically related to unsuccessful retreatment tuberculosis. Logistic regression showed that regular taking of a drug $(p=0.000 ; O R=29.52$; $95 \% \mathrm{Cl}=10.97-79.4)$ was the strongest risk factor related to unsuccessful retreatment of tuberculosis. Conclusion: The strongest risk factor was regularly taking of a drug. District health offices need to conduct a tracking system of patients who do not take medication on schedule, ensuring regular tuberculosis medication, correct medication, and sputum examination of late-stage intensive tuberculosis patients.

Keywords: tuberculosis; unsuccessful retreatment; risk factor

${ }^{1}$ Dinas Kesehatan Provinsi Daerah Istimewa Yogyakarta (Email: tbc_harna@yahoo.com)

${ }^{2}$ Pusat Kedokteran Tropis, Universitas Gadjah Mada 


\section{PENDAHULUAN}

Tuberkulosis (TB) adalah penyakit menular langsung akibat Mycobacterium tuberculosis. Sebagian besar Mycobacterium tuberculosis menyerang paru, tetapi juga mengenai organ tubuh lain (ekstra paru). Data World Health Organization (WHO) menunjukkan bahwa insidensi TB sedunia pada tahun 2013 sebesar 9 juta kasus baru (range antara 8,6-9,4 juta kasus), dengan angka insidensi sebesar 126/100.000 populasi dan kematian sebesar 1,4 juta kasus. Sebagian besar kasus TB berasal dari regional Asia (56\%), Afrika (29\%), Mediterania Timur (8\%), Eropa (4\%), dan Amerika (3\%). Indonesia adalah satu dari enam negara yang memiliki angka insidensi tertinggi (1). Insidensi TB di Indonesia semakin diperberat dengan kemunculan koinfeksi TB-HIV dan TB MDR (multi drug resistance). Prevalensi HIV pada pasien TB di Indonesia sebesar 2,8\%. Prevalensi TB MDR di antara kasus TB baru di Indonesia sebesar $2 \%$, sedangkan prevalensi TB MDR di antara kasus TB pengobatan ulang sebesar 20\% (2).

Pengobatan ulang pasien TB memerlukan waktu yang lebih lama (minimal 8 bulan) menggunakan injeksi Streptomisin setiap hari selama 8 minggu pertama, diberikan untuk pasien TB BTA positif yang pernah diobati sebelumnya meliputi pasien TB kambuh, pasien TB gagal (failure), dan pasien TB setelah putus berobat (default). Penemuan dan pengobatan pasien TB merupakan cara terbaik dalam upaya menurunkan insidensi TB di masyarakat. Pengobatan TB bertujuan untuk menyembuhkan pasien, mencegah kematian, mencegah kekambuhan, memutuskan rantai penularan, dan mencegah terjadinya kekebalan kuman terhadap obat anti tuberkulosis (OAT). Pengawasan langsung oleh seorang pengawas menelan obat (PMO) untuk menjamin kepatuhan pasien menelan obat (2).

Angka keberhasilan pengobatan ulang pasien TB di 11 negara anggota WHO regional SEARO (South-East Asia Regional Office) tahun 2009 jauh lebih rendah dibandingkan pada pasien baru yaitu $75 \%$ berbanding 88\%. Angka keberhasilan di Indonesia sebesar 72\% berbanding $91 \% 3$ dan di Yogyakarta sebesar 75,4\% berbanding 86,16\% (4). Rendahnya angka keberhasilan pengobatan ini disebabkan masih tingginya pasien yang berhenti minum obat (default) karena berbagai alasan, gagal (failure), dan mati. Banyak penelitian yang menunjukkan faktor-faktor yang berhubungan dengan kegagalan pengobatan ulang TB antara lain status HIV (5,7), buta huruf, pekerjaan, kebiasaan minum alhokol (6), kepatuhan pengobatan $(7,8)$, umur, lamanya merasakan gejala TB $(7)$, tipe pasien $(9,10)$.
Pasien TB pengobatan ulang yang putus berobat dan gagal akan tetap menjadi sumber penularan. Pasien itu berisiko menjadi pasien TB MDR yang membutuhkan pengobatan lebih lama dan lebih mahal, dengan angka keberhasilan lebih rendah. Lima di antara sembilan kriteria suspek TB MDR berkaitan dengan pasien TB pengobatan ulang (2). Sampai saat ini penyebab kegagalan pengobatan pasien TB belum bisa teridentifikasi dengan jelas. Oleh karena itu penelitian ini dilakukan untuk mengetahui faktor risiko kegagalan pengobatan pasien TB pengobatan ulang di Yogyakarta tahun 2008-2014.

\section{METODE}

Penelitian analitik observasional ini menggunakan rancangan penelitian case control. Semua responden mulai diteliti sejak dinyatakan selesai menjalani pengobatan TB (outcome). Outcome dikategorikan menjadi pengobatan tidak berhasil sebagai kelompok kasus dan pengobatan berhasil sebagai kelompok kontrol. Penelitian dilakukan terhadap paparan (exposure) meliputi keteraturan minum obat, gradasi BTA positif, status konversi BTA, penyakit lain, tipe pasien TB ulang, dan jenis fasilitas layanan kesehatan.

Populasi adalah semua pasien TB pengobatan ulang di 5 kabupaten/kota di Yogyakarta. Data yang digunakan adalah register pasien TB (TB 03) dan kartu pengobatan (TB 01) di seluruh Yogyakarta pada tahun 2008-2014. Kriteria inklusi responden yaitu tercatat di dalam register TB 03 kabupaten/kota di Yogyakarta antara tahun 2008-2014, tercatat dengan tipe kambuh, pengobatan setelah putus berobat, pindahan, atau gagal, dan diobati dengan OAT kategori II. Kriteria eksklusi adalah tercatat sebagai pasien TB ekstra paru, tidak terdapat hasil pemeriksaan dahak sebelum pengobatan, hasil pemeriksaan dahak sebelum pengobatan BTA negatif, tidak ada hasil pemeriksaan dahak pada akhir bulan ketiga (akhir fase intensif), TB 01 tidak tersedia dan catatan medis tidak lengkap. Kasus dipilih secara total sampling melibatkan 138 pasien, sedangkan kontrol dipilih secara sistematic sampling dari daftar pasien TB pengobatan ulang yang memenuhi kriteria inklusi dan eksklusi. Penelitian dilaksanakan di dinas kesehatan provinsi Yogyakarta dan 5 dinas kesehatan kabupaten/kota yang ada di Yogyakarta. Pengambilan data berlangsung pada bulan Desember 2015 sampai Februari 2016 menggunakan formulir rekap data pasien TB.

Kegagalan pengobatan (unsuccessfully treatment) adalah hasil akhir pengobatan ulang pasien TB dengan OAT kategori II yang tidak diharapkan oleh program 
nasional pengendalian $\mathrm{TB}$, meliputi putus berobat (drop out) atau tidak dapat dilacak (lost to follow-up), gagal (failure), pindah (transfer-out) atau tidak dapat dievaluasi, meninggal (died). Skala data nominal dengan kategori ya dan tidak.

Keteraturan minum obat adalah kepatuhan pasien TB dalam minum OAT kategori II sesuai pedoman nasional penanggulangan TB di Indonesia. Skala data nominal dengan kategori tidak teratur jika pasien TB tidak minum obat setiap hari pada fase awal atau $3 \mathrm{kali}$ seminggu pada fase lanjutan, dan teratur jika pasien TB minum obat setiap hari pada fase awal dan 3 kali seminggu pada fase lanjutan.

Gradasi BTA positif adalah hasil pemeriksaan mikroskopis dahak pasien TB pengobatan ulang yang dinyatakan dalam tiga jenis menurut skala IUATLD (BTA $3+, 2+, 1+$ ). Skala data rasio dengan kategori gradasi tinggi jika BTA 3+ atau 2+ dan BTA rendah jika gradasi BTA 1+. Penyakit lain adalah penyakit selain TB yang juga dialami oleh pasien TB pengobatan ulang selama menjalani pengobatan TB dengan kategori ada jika pasien TB mengidap penyakit selain TB dan tidak ada jika pasien TB tidak mengidap penyakit selain TB

Status konversi BTA adalah perubahan hasil pemeriksaan mikroskopis dahak dari BTA positif pada awal pengobatan menjadi BTA negatif pada akhir pengobatan fase intensif (3 bulan). Skala data nominal dengan kategori: tidak konversi jika hasil pemeriksaan tetap BTA positif dan konversi jika hasil pemeriksaan mikroskopis menjadi BTA negatif

Tipe pasien TB pengobatan ulang adalah pengelompokan pasien TB yang diobati dengan OAT kategori II berdasarkan riwayat pengobatan sebelumnya dan tercatat di dalam register pasien TB (TB 03) atau kartu pengobatan (TB 01). Skala data nominal dengan kategori: pengobatan setelah putus berobat (defaulter atau lost to follow up)/ pindahan (transfer-in)/ pengobatan setelah gagal (failure), dan kambuh (relaps). Jenis fasilitas layanan kesehatan adalah nomenklatur fasilitas layanan kesehatan yang tercatat di dinas kesehatan (provinsi/kabupaten/kota). Skala data nominal dengan kategori: rumah sakit dan pusat kesehatan masyarakat (puskesmas)

Analisis univariat untuk melihat distribusi frekuensi masing-masing variabel, analisis bivariat dengan uji chi-square untuk mengetahui hubungan antara masing-masing variabel bebas dengan variabel terikat, dan analisis multivariat dengan uji regresi logistik berganda untuk melihat variabel bebas yang paling besar berpengaruh terhadap variabel terikat. Tingkat signifikansi ditetapkan pada $\mathrm{p}<0,05$ dengan tingkat kepercayaan 95\%.
Stigma negatif penyakit TB masih terjadi di masyarakat Indonesia khususnya Yogyakarta, oleh karena itu peneliti menjamin kerahasiaan data pasien yang menjadi responden dalam penelitian dengan cara menghapus nama dan alamat pada formulir rekap data pasien TB.

\section{HASIL}

Tabel 1. Ciri responden

\begin{tabular}{|c|c|c|}
\hline Karakteristik & Kasus (\%) & Kontrol (\%) \\
\hline \multicolumn{3}{|l|}{ Jenis kelamin } \\
\hline Laki-laki & 60,56 & 61,27 \\
\hline Perempuan & 39,44 & 38,73 \\
\hline \multicolumn{3}{|l|}{ Tempat pengobatan } \\
\hline Yogyakarta & 35,92 & 23,94 \\
\hline Bantul & 14,08 & 24,65 \\
\hline Kulonprogo & 11,27 & 7,04 \\
\hline Gunungkidul & 13,38 & 12,68 \\
\hline Sleman & 25,35 & 31,69 \\
\hline \multicolumn{3}{|l|}{ Tahun pengobatan } \\
\hline 2008 & 17,61 & 20,42 \\
\hline 2009 & 14,08 & 14,79 \\
\hline 2010 & 19,01 & 17,61 \\
\hline 2011 & 13,38 & 10,56 \\
\hline 2012 & 14,08 & 12,68 \\
\hline 2013 & 16,90 & 16,90 \\
\hline 2014 & 4,93 & 7,04 \\
\hline \multicolumn{3}{|l|}{ Keteraturan minum obat } \\
\hline Tidak teratur & 55,63 & 3,52 \\
\hline Teratur & 44,37 & 96,48 \\
\hline \multicolumn{3}{|l|}{ Gradasi BTA positif } \\
\hline Tinggi & 22,54 & 30,28 \\
\hline Rendah & 77,46 & 69,72 \\
\hline \multicolumn{3}{|l|}{ Penyakit lain } \\
\hline Ada & 3,52 & 2,82 \\
\hline Tidak ada & 96,48 & 97,18 \\
\hline \multicolumn{3}{|l|}{ Status konversi } \\
\hline Tidak konversi & 47,18 & 7,04 \\
\hline Konversi & 52,82 & 92,96 \\
\hline \multicolumn{3}{|l|}{ Tipe pasien } \\
\hline $\begin{array}{l}\text { Gagal/ } \\
\text { defaulter/pindahan }\end{array}$ & 28,17 & 18,31 \\
\hline $\begin{array}{l}\text { Kambuh } \\
\text { Jenis fasilitas layanan k }\end{array}$ & 71,83 & 81,69 \\
\hline Rumah sakit & 15,49 & 6,34 \\
\hline Puskesmas & 84,51 & 93,66 \\
\hline
\end{tabular}

Populasi pasien TB pengobatan ulang di wilayah Yogyakarta tahun 2008-2014 sebanyak 850 pasien, 655 pasien memenuhi kriteria sampel, sedangkan 95 pasien dikeluarkan dari daftar karena hasil pemeriksaan BTA pada awal pengobatan negatif (20 pasien), teregister ganda (21 pasien), TB 01/catatan medis (CM) tidak ada (29 pasien), dan tidak ada hasil pemeriksaan BTA pada akhir fase intensif (25 pasien). Dari 655 pasien, 142 pasien mengalami kegagalan pengobatan dan diambil sebagai kelompok kasus, sedangkan 142 dari 513 pasien sembuh atau pengobatan lengkap. Penelitian ini menemukan lebih dari 50\% responden tidak teratur minum obat pada kelompok kasus. Persentase tertinggi adalah orang yang kambuh. 
Tabel 3. Faktor kegagalan pengobatan ulang

\begin{tabular}{|c|c|c|c|}
\hline Variabel & $\begin{array}{c}\text { Kasus } \\
(n=142)\end{array}$ & $\begin{array}{c}\text { Kontrol } \\
(n=142)\end{array}$ & $\begin{array}{c}\text { OR } \\
(95 \% \mathrm{CI})\end{array}$ \\
\hline \multicolumn{4}{|c|}{ Keteraturan minum obat } \\
\hline Tidak teratur & 79 & 5 & $34,36^{*}$ \\
\hline Teratur & 63 & 137 & $(13,26-89,00)$ \\
\hline \multicolumn{4}{|c|}{ Gradasi BTA Positif } \\
\hline Tinggi & 32 & 43 & 0,67 \\
\hline Rendah & 110 & 99 & $(0,39-1,14)$ \\
\hline \multicolumn{4}{|l|}{ Penyakit lain } \\
\hline Ada & 5 & 4 & 1,26 \\
\hline Tidak ada & 137 & 138 & $(0,33-4,79)$ \\
\hline \multicolumn{4}{|c|}{ Status konversi BTA } \\
\hline Tidak konversi & 67 & 10 & $11,79^{*}$ \\
\hline Konversi & 75 & 132 & $(5,73-24,28)$ \\
\hline \multicolumn{4}{|l|}{ Tipe pasien } \\
\hline \multicolumn{4}{|l|}{ Gagal/ } \\
\hline $\begin{array}{l}\text { defaulter/ } \\
\text { pindahan }\end{array}$ & 40 & 26 & $\begin{array}{c}1,75^{*} \\
(0,99-3,07)\end{array}$ \\
\hline Kambuh & 102 & 116 & \\
\hline \multicolumn{4}{|l|}{ Jenis fasyankes } \\
\hline Rumah sakit & 22 & 9 & $2,71^{*}$ \\
\hline Puskesmas & 120 & 133 & $(1,20-6,11)$ \\
\hline
\end{tabular}

Tabel 4. Faktor risiko kegagalan pengobatan ulang

\begin{tabular}{|c|c|c|c|}
\hline Variabel & OR & $95 \% \mathrm{CI}$ & $\overline{P \text {-Value }}$ \\
\hline Model 1 & & & \\
\hline $\begin{array}{l}\text { Keteraturan } \\
\text { minum obat }\end{array}$ & 30,20 & $11,15-81,79$ & 0,000 \\
\hline $\begin{array}{l}\text { Gradasi BTA } \\
\text { positif }\end{array}$ & 0,86 & $0,42-1,75$ & 0,675 \\
\hline $\begin{array}{l}\text { Status konversi } \\
\text { BTA }\end{array}$ & 9,90 & $4,37-22,40$ & 0,000 \\
\hline Tipe pasien TB & 1,91 & $0,91-4,00$ & 0,087 \\
\hline $\begin{array}{l}\text { Jenis fasilitas } \\
\text { layanan } \\
\text { kesehatan } \\
\text { Model } 2\end{array}$ & 3,62 & $1,34-9,81$ & 0,011 \\
\hline $\begin{array}{l}\text { Keteraturan } \\
\text { minum obat }\end{array}$ & 30,36 & $11,22-82,18$ & 0,000 \\
\hline $\begin{array}{l}\text { Status konversi } \\
\text { BTA }\end{array}$ & 9,86 & $4,36-22,32$ & 0,000 \\
\hline Tipe pasien TB & 1,95 & $0,94-4,07$ & 0,075 \\
\hline $\begin{array}{l}\text { Jenis fasilitas } \\
\text { layanan } \\
\text { kesehatan } \\
\text { Model } 3\end{array}$ & 3,60 & $1,33-9,73$ & 0,011 \\
\hline $\begin{array}{l}\text { Keteraturan } \\
\text { minum obat }\end{array}$ & 29,52 & $10,97-79,40$ & 0,000 \\
\hline $\begin{array}{l}\text { Status konversi } \\
\text { BTA }\end{array}$ & 9,87 & $4,39-22,21$ & 0,000 \\
\hline $\begin{array}{l}\text { Jenis fasilitas } \\
\text { layanan } \\
\text { kesehatan } \\
\text { Model } 4\end{array}$ & 3,55 & $1,32-9,57$ & 0,012 \\
\hline $\begin{array}{l}\text { Keteraturan } \\
\text { minum obat }\end{array}$ & 28,63 & $10,74-76,30$ & 0,000 \\
\hline $\begin{array}{l}\text { Status konversi } \\
\text { BTA }\end{array}$ & 9,19 & $4,14-20,39$ & 0,000 \\
\hline
\end{tabular}

Tabel 3 menunjukkan responden yang tidak teratur minum obat memiliki risiko mengalami kegagalan pengobatan ulang TB sebesar 34,36 kali lebih besar dibandingkan dengan responden yang teratur minum obat. Gradasi BTA positif tinggi tidak berhubungan dengan kegagalan pengobatan ulang TB. Responden dengan gradasi BTA positif tinggi berisiko mengalami kegagalan pengobatan ulang TB sebesar 0,67 kali dibandingkan dengan responden gradasi BTA positif rendah, tetapi nilai CI menunjukkan gradasi BTA positif bukan merupakan faktor risiko kegagalan pengobatan ulang TB. Penyakit lain bukan merupakan faktor risiko kegagalan pengobatan ulang TB. Sementara Tabel 4 menunjukkan minum obat TB secara tidak teratur meningkatkan peluang kegagalan pengobatan sebesar 29,52 kali (Model 3).

\section{BAHASAN}

Obat anti tuberkulosis (OAT) adalah komponen terpenting dalam pengobatan TB. Pengobatan TB merupakan upaya paling efisien untuk mencegah penyebaran kuman TB lebih lanjut (11). Penelitian ini membuktikan pada pasien TB pengobatan ulang dengan OAT kategori II yang minum OAT tidak teratur mempunyai risiko kegagalan sebesar 34,36 kali lebih besar dibanding pasien yang teratur minum OAT, yaitu setiap hari pada fase awal dan tiga kali seminggu pada fase lanjutan. Hal ini sejalan dengan hasil penelitian di satu rumah sakit rujukan TB milik pemerintah Uganda yang menunjukkan bahwa minum OAT tidak teratur meningkatkan risiko kegagalan pengobatan TB sebesar 2,39 kali (7). Keluarga menjadi faktor yang sangat berpengaruh dalam menentukan keyakinan dan nilai kesehatan individu serta dapat menentukan program pengobatan yang dapat diterima. Kualitas interaksi profesional kesehatan dan pasien merupakan bagian penting dalam menentukan derajat kepatuhan (12).

Gradasi BTA positif menunjukkan tingkat penularan dan keparahan penyakit. Semakin tinggi gradasi BTA positif berarti semakin parah penyakit TB yg dialami pasien, dan semakin tinggi tingkat penularannya.13 Pasien TB dengan hasil pemeriksaan BTA positif merupakan sumber penularan TB yang terbesar yaitu $65 \%$, sedangkan pasien TB BTA negatif dengan hasil kultur positif sebesar $26 \%$, dan pasien TB dengan kultur negatif dan foto toraks positif sebesar $17 \%$ (11).

Penelitian ini tidak dapat membuktikan bahwa gradasi BTA positiftinggi $(2+$ dan $3+$ ) meningkatkan risiko kegagalan pengobatan ulang TB. Hasil penelitian ini berbeda dengan penelitian di India yang menunjukkan bahwa pasien TB BTA positif gradasi 3+ lebih berisiko mengalami gagal (failure) dan mati dibandingkan gradasi di bawahnya (14). Penelitian Gopi et al. di India Selatan juga menunjukkan tren angka keberhasilan pengobatan menurun seiring dengan semakin tinggi gradasi BTA sebelum pengoba- 
tan dan secara statistik bermakna (15). Perbedaan hasil penelitian tersebut menunjukkan bahwa gradasi BTA merupakan salah satu variabel yang perlu diperhatikan dalam pengobatan TB. Pengobatan TB yang adekuat menurunkan jumlah kuman secara cepat (11).

Penyakit selain TB yang diderita oleh pasien TB menyebabkan beberapa pengobatan TB harus diobservasi secara lebih ketat, ditunda, dihentikan untuk sementara, atau dimodifikasi sehingga memengaruhi lama dan hasil pengobatan (11). Penelitian ini tidak dapat membuktikan bahwa adanya penyakit lain pada pasien ulang TB akan meningkatkan risiko kegagalan pengobatan Kemungkinan penyebab dari jumlah responden dengan penyakit lain sangat sedikit (5 pada kelompok kasus dan 4 pada kelompok kontrol) dan penanganan pasien TB dengan penyakit lain pada awalnya dirujuk ke rumah sakit yang mempunyai unit spesialistik, sehingga pasien bisa diobati dengan tepat kemudian dirujuk balik ke puskesmas.

Pemeriksaan ulang dahak secara mikroskopis pada akhir fase intensif dilakukan untuk mengetahui konversi BTA dari positif menjadi negatif. Semakin tinggi angka konversi akan semakin tinggi angka keberhasilan pengobatan (11). Penelitian ini dapat membuktikan bahwa pasien yang tidak mengalami konversi BTA mempunyai risiko kegagalan pengobatan ulang TB sebesar 11,79 kali lebih besar daripada pasien yang mengalami konversi BTA. Hasil penelitian ini sejalan dengan hasil penelitian sebelumnya di India Selatan. Penelitian itu menemukan status konversi pasien TB berhubungan dengan kesembuhan pasien (15). Angka kesembuhan pasien TB pada pasien yang tidak mengalami konversi lebih rendah dibandingkan dengan pasien yang mengalami konversi (16).

Pasien TB tipe kambuh sudah pernah menyelesaikan pengobatan TB dengan hasil akhir sembuh atau pengobatan lengkap. Pasien kategori gagal/defaulter/ pindahan belum pernah menyelesaikan pengobatan TB dengan hasil sembuh atau pengobatan lengkap. Kedua tipe tersebut diduga mempunyai perilaku pengobatan yang berbeda, sehingga akan memengaruhi hasil pengobatan ulang. Penelitian ini tidak membuktikan bahwa pasien tipe gagal/ defaulter/pindahan memiliki risiko kegagalan pengobatan ulang TB lebih besar dibandingkan pasien tipe kambuh. Hasil ini berbeda dengan penelitian di India yang menunjukkan hubungan bermakna antara tipe pasien TB ulang dengan hasil pengobatan (17). Penelitian Mukherjee et al. di West Bengal, India menunjukkan hubungan antara tipe pasien dengan kegagalan pengobatan (18). Perbedaan hasil penelitian di India dan Yogyakarta disebabkan perbedaan pengelompokan tipe pasien.
Pengaturan kewenangan terhadap fasilitas layanan kesehatan bertujuan agar layanan kesehatan dapat dilakukan secara berjenjang dan merata. Puskesmas berwenang untuk menyelenggarakan upaya kesehatan perorangan dan upaya kesehatan masyarakat (19), sedangkan rumah sakit hanya menyelenggarakan layanan kesehatan perorangan di rumah sakit (20). Karakteristik itu diduga berdampak pada layanan pengobatan ulang pasien TB selama waktu 8 bulan.

Penelitian ini membuktikan bahwa pengobatan ulang pasien TB di rumah sakit memiliki risiko kegagalan pengobatan sebesar 2,71 kali lebih besar dibandingkan pengobatan di puskesmas. Hal ini sesuai dengan hasil monitoring dan evaluasi program nasional TB yang menyebutkan bahwa angka keberhasilan pengobatan TB di rumah sakit di Indonesia masih dibawah 50\% dengan angka putus berobat mencapai $50-85 \%$ (21). Tingginya angka putus berobat pasien TB di rumah sakit disebabkan oleh ketidakmampuan rumah sakit untuk melacak pasien TB. Jika pasien satu kali saja tidak berkunjung untuk mengambil OAT pada fase awal (intensif), maka pemberi layanan TB harus menghubungi pasien tersebut dalam satu hari setelah OAT habis, sedangkan pada fase lanjutan adalah satu minggu setelah OAT habis. Penting untuk mengetahui penyebab ketidakhadiran pasien sehingga tindakan yang tepat diambil dan pengobatan dilanjutkan (21).

Model terbaik yang menjelaskan tiga variabel bermakna secara statistik adalah variabel keteraturan minum obat, status konversi BTA, dan jenis fasilitas layanan kesehatan. Keteraturan minum obat TB merupakan faktor risiko terkuat yang meningkatkan peluang kegagalan pengobatan.

\section{SIMPULAN}

Faktor risiko kegagalan pengobatan ulang pada pasien TB di Yogyakarta adalah ketidakteraturan minum obat, tidak mengalami konversi BTA pada akhir bulan ketiga, dan diobati di rumah sakit. Gradasi BTA, penyakit lain, dan tipe pengobatan bukan merupakan faktor risiko untuk gagal dalam pengobatan ulang pasien TB. Dinas kesehatan perlu melakukan sistem pelacakan pasien yang tidak mengambil obat sesuai jadwal, memastikan keteraturan minum obat pasien TB, cara minum obat yang benar, dan pemeriksaan ulang dahak pasien TB akhir fase intensif. 


\section{Abstrak}

Tujuan: Penelitian ini bertujuan mengetahui faktor risiko kegagalan pengobatan ulang pada pasien tuberkulosis di Yogyakarta. Metode: Studi kasus kontrol berbasis data register pasien tuberkulosis (TB 03) di 5 kabupaten/kota di Yogyakarta dan kartu pengobatan (TB 01) di fasilitas layanan kesehatan tahun 2008-2014. Kasus adalah pasien tuberkulosis pengobatan ulang dengan kegagalan pengobatan, sedangkan kontrol adalah pasien tuberkulosis dengan pengobatan ulang yang sembuh atau pengobatan lengkap. Sampel berjumlah 142 kasus dan 142 kontrol. Data dianalisis menggunakan uji chi square dan uji regresi logistik berganda pada tingkat signifikansi $\mathrm{p}<0,05$ dan tingkat kepercayaan 95\%. Hasil: Analisis bivariat menunjukkan keteraturan minum obat, status konversi BTA dan jenis fasilitas layanan kesehatan termasuk faktor risiko dari kegagalan pengobatan ulang pasien tuberkulosis. Hasil uji regresi logistik menunjukkan keteraturan minum obat merupakan faktor risiko terkuat kegagalan pengobatan ulang pasien tuberkulosis. Simpulan: Faktor risiko terkuat secara teratur untuk mengambil obat. Dinas kesehatan provinsi Yogyakarta dan kabupaten/kota perlu melakukan sistem pelacakan pasien yang tidak minum obat sesuai jadwal, memastikan pengobatan tuberkulosis reguler, minum obat yang benar, dan pemeriksaan ulang dahak pasien tuberkulosis akhir fase intensif.

Kata kunci: tuberkulosis; kegagalan pengobatan ulang; faktor risiko

\section{PUSTAKA}

1. World Health Organization. Global Tuberculosis Report 2014. Geneva, Switzerland; 2014.

2. Kementerian Kesehatan. Pedoman Nasional Penanggulangan Tuberkulosis. Jakarta; 2011.

3. World Health Organization. Tuberculosis Control in the SEARO 2012. India; 2012.

4. Dinas Kesehatan. Laporan Seksi Pengendalian Penyakit. Yogyakarta; 2014.

5. Chakaya JM, Kibuga D, Githui WA, Mansoer JR, Gakiria G, Kwamanga D, Maende J. Tuberculosis re-treatment outcomes within the public service in Nairobi, Kenya. East African medical journal. 2002;79(1):11-5.

6. Jones-López, E.C., Ayakaka, I., Levin, J., Reilly, N., Mumbowa, F., Dryden-Peterson, S., Nyakoojo, G., Fennelly, K., Temple, B., Nakubulwa, S. and Joloba, M.L., 2011. Effectiveness of the standard WHO recommended retreatment regimen (category II) for tuberculosis in Kampala, Uganda: a prospective cohort study. PLoS medicine, 8(3), p.e1000427.
7. Bhagat V, Gattani P. The Southeast Asian journal of tropical medicine and public health. Southeast Asian J Trop Med Public Health. SEAMEO Central Coordinating Board for Tropical Medicine and Public Health; 2010;41(5):1153-63.

8. Picon PD, Rizzon CF, Bassanesi SL, Silva LC, Giustina MD. Retreatment of tuberculosis patients in the city of Porto Alegre, Brazil: outcomes. Jornal Brasileiro de Pneumologia. 2011 Aug;37(4):504-11.

9. Takarinda KC, Harries AD, Srinath S, Mutasa-Apollo T, Sandy C, Mugurungi O. Treatment outcomes of adult patients with recurrent tuberculosis in relation to HIV status in Zimbabwe: a retrospective record review. BMC Public Health. 2012 Dec;12(1):124.

10. Dooley KE, Lahlou O, Knudsen J, Elmessaoudi MD, Cherkaoui I, El Aouad R. Risk factors for tuberculosis treatment failure, default, or relapse and outcomes of retreatment in Morocco. BMC public health. 2011 Dec;11(1):140.

11. Departemen Kesehatan. Pedoman Nasional Pengendalian Tuberkulosis. Jakarta; 2014.

12. Niven N. Psikologi Kesehatan: Pengantar Untuk Perawat \& Profesional Kesehatan Lain. Jakarta: EGC; 2012.

13. Akhtar M, Bretzel G, Boulahbal F, Dawson D, Fattorini L, Feldmann K, Frieden T, Havelková M, de Kantor IN, Kim SJ, Küchler R. Technical guide: sputum examination for tuberculosis by direct microscopy in lowincome countries. Paris, France: International Union Against Tuberculosis and Lung Disease. 2000.

14. Rajpal S, Dhingra VK, Aggarwal JK. Sputum grading as predictor of treatment outcome in pulmonary tuberculosis. Indian Journal of Tuberculosis. 2002;49(3):139-42.

15. Gopi PG, Chandrasekaran V, Subramani R, Santha T. Association of conversion \& cure with initial smear grading among new smear positive pulmonary tuberculosis patients treated with Category I regimen. Indian Journal of Medical Research. 2006 Jun 1;123(6):807.

16. Tiwari S, Kumar A, Kapoor SK. Relationship between sputum smear grading and smear conversion rate and treatment outcome in the patients of pulmonary tuberculosis undergoing dots-a prospective cohort study. Indian Journal Tuberculosis. 2012 Jul;59(3):135-40.

17. Prasanna KT, Arun BJ, Uma MK. A prospective study of sputum conversion rate and cure rate in smear positive retreatment patients under RNTCP in rural population. Journal of Evolution of Medical and Dental Sciences. 2015 Jun 8;4(46):7900-19.

18. Mukherjee A, Sarkar A, Saha I, Biswas B, Bhattacharyya P, Ps B. Outcomes of different subgroups of smear- positive retreatment patients under RNTCP in rural West Bengal, India Outcomes of different subgroups of smear-positive retreatment patients under RNTCP in rural West Bengal, India. Rural Remote Health. 2009;9.

19. Kementerian Kesehatan. Keputusan Menteri Kesehatan No. 75 tahun 2014 tentang Puskesmas. Jakarta; 2014.

20. Kementerian hukum dan hak asasi manusia $\mathrm{R}$. Undang-undang Republik Indonesia No.44 tahun 2009 tentang Rumah Sakit. Jakarta; 2009.

21. Kementerian Kesehatan. Pedoman Nasional Pelayanan Kedokteran Tata Laksana Tuberkulosis. Jakarta; 2013. 